\title{
ТЕХНОЛОГІЯ ВИГОТОВЛЕННЯ І МАТЕМАТИЧНІ МОДЕЛІ АПАРАТІВ ВИСОКОГО ТИСКУ
}

\author{
Павло Федірко, к. т. н., Владлен Девін, к. т. н., Василь Ткачук, к. т. н., \\ Василь Бурдега, к. т. н. \\ Подільський державний аграрно-технічний університет, \\ вул. Шевченка, 13, м. Кам'янещь-Подільський, Хмельнищька обл., Украӥна, \\ e-mail:polfedirko@gmail.com,dvvkp.123@gmail.com,twskmg@gmail.com, \\ burdega_vasil@ukr.net
}

https://doi.org/10.31734/agroengineering2021.25.143

\author{
Федірко П., Девін В., Ткачук В., Бурдега В. Технологія виготовлення і математичні моделі апаратів високого \\ тиску
}

Апарати високого тиску широко використовують у галузі переробки сільськогосподарської продукції, харчових виробництв, у різних галузях промисловості. Від досконалості їхньої конструкції залежать надійність роботи апаратів, безпека обслуговуючого персоналу, продуктивність і в кінцевому підсумку собівартість продукції. Особливістю проєктування апаратів є те, що їх розрахунок регламентується численними нормативними документами - державними і галузевими стандартами, нормами тощо.

У результаті моделювання й розрахунку проаналізовано апарати високого тиску у вигляді циліндра в одно-, дво- $\mathrm{i}$ тришаровому виконанні, визначено еквівалентні напруження і натяги. Визначено вагові співвідношення. Апарати в тришаровому виконанні є міцними і найменш металомісткими, що суттєво зменшує вагу.

Результатом представленої роботи є висновок про те, що спроєктувати апарат високого тиску на основі багатошарової конструкції є більш доцільним. Використання представлених теоретичних викладок дозволить дотриматися всіх вимог чинних нормативних документів, зменшити металомісткість устаткування, збільшити надійність його роботи, знизити собівартість i, зрештою, підвищити якість продукції, яка виробляється. При цьому основою розрахунків $є$ правильний вибір і складання розрахункових схем, опрацювання різних типів конструкцій та алгоритмів. Основними методиками розрахунку апаратів високого тиску є використання загального рівняння масообміну із застосуванням формули Ламе та визначенням еквівалентних напружень в елементах апарата високого тиску.

Подальше застосування теоретичних розрахунків на стадії проєктування дасть змогу розробникам знайти оптимальні геометричні форми й розміри вузлів конструкції, виходячи з навантажень, які реально діють у процесі експлуатації установки, що не завжди можливо зробити з використанням аналітичних залежностей.

Ключові слова: апарат високого тиску, багатошарові конструкції, циліндричні обичайки, масообмін, формула Ламе.

Fedirko P., Devin V., Tkachuk V., Burdeha V. Manufacturing technology and mathematical models of high-pressure units

High-pressure equipment is widely used in the field of agricultural processing, food production, in various industries. The perfection of their design depends on the device reliability, safety of service personnel, productivity and ultimately the cost of production. A feature of the device design is that their calculation is governed by numerous regulatory documents - state and industry standards, norms etc.

As a result of modeling and calculation, the high-pressure devices in the form of the cylinder in one-, two- and three-layer execution are analyzed, equivalent stresses and tensions are defined. The weight ratios are determined. The devices in threelayer design are strong and the least metal-intensive, which significantly reduces weight.

The result of the presented work is to make conclusion that it is more expedient to design a high-pressure apparatus based on a multilayer structure. The use of the presented theoretical calculations makes it possible to fulfill all the requirements imposed by the current regulatory documents, to reduce the metal consumption of equipment, to increase the reliability of its operation and reduce the cost, and, finally, to improve the product quality. The basis of calculations is made by the correct choice and compilation of calculation schemes, processing of different types of structures and algorithms. The main methods of calculating high-pressure apparatus include the use of general equation of mass transfer using the Lamé formula and the determination of equivalent stresses in the elements of a high-pressure apparatus.

A further application of theoretical calculations at the design stage will allow developers to find the optimal geometric shapes and sizes of structural units, based on the loads actually acting during the installation operation, which is not always possible using analytical dependencies.

Key words: high-pressure apparatus, multilayer structures, cylindrical shells, mass transfer, Lamés formula. 
Постановка проблеми. Апарати високого тиску широко використовують у галузі переробки сільськогосподарської продукції, харчових виробництв, у різних галузях промисловості. Від досконалості їхньої конструкції залежать надійність роботи апаратів, безпека обслуговуючого персоналу, продуктивність і в кінцевому підсумку собівартість продукції. Процес конструювання апаратів високого тиску неможливий без складання математичних моделей, застосування складного математичного апарату i сучасного комп’ютерного забезпечення.

Особливістю проєктування апаратів високого тиску $\epsilon$ те, що їх розрахунок регламентується численними нормативними документами: державними, галузевими стандартами, нормами, технічними умовами тощо. Тому для моделювання й розрахунку апаратів високого тиску нами було проаналізовано і наглядно доведено, що використання багатошарових циліндрів $є$ доцільним.

Аналіз останніх досліджень і публікацій. Конструкції посудин та апаратів високого тиску визначаються вимогами хіміко-технологічного процесу, експлуатаційними параметрами й характеристиками (тиск, температура, властивості робочого середовища, режим роботи), продуктивністю та оснащеністю технологічним устаткуванням заводів-виробників, умовами транспортування i монтажу. Конструкції посудин високого тиску повинні відповідати вимогам нормативному документа НПАОП 0.00-1.07-94 [6]. Розрахунок на міцність посудини або апарата зводиться до перевірки виконання умов міцності, а в низці випадків і стійкості його окремих елементів, таких як обичайки, кришки, днища тощо. Розрахунок циліндричних і конічних обичайок, випуклих і плоских днищ та кришок регламентує стандарт, загальні технічні вимоги - ГОСТ Р 52630-2012 [4].

Для розрахунку будь-якого елементу обладнання, крім його геометричних розмірів, необхідно задати такі вихідні дані: марку сталі, розрахункову температуру, розрахунковий внутрішній надлишковий або зовнішній тиск, коефіцієнт запасу міцності зварних швів, модуль поздовжньої пружності (під час розрахунку елементів устаткування на стійкість). Розрахунок проводять для робочих умов і умов гідравлічних випробувань (розрахункову температуру приймають у цьому разі рівною $\left.60{ }^{\circ} \mathrm{C}\right)$ [5]. Марку сталі вибирають залежно від корозійних властивостей робочого середовища 3 умови, що швидкість корозії не повинна перевищувати 0,1 мм/рік. Розрахункову температуру використовують для визначення фізикомеханічних характеристик матеріалу й допустимих напружень, а також під час розрахунку на міцність 3 урахуванням температурних впливів [7]. При цьому основою розрахунків $\epsilon$ правильний вибір і складання розрахункових схем, опрацювання різних типів конструкцій та алгоритмів. Основними методиками розрахунку апаратів високого тиску є використання загального рівняння масообміну із застосуванням формули Ламе та визначенням еквівалентних напружень в елементах апарата високого тиску.

Постановка завдання. Наше завдання полягає у вдосконаленні методики проєктування апаратів високого тиску за рахунок використання багатошарових оболонок.

Виклад основного матеріалу. Алгоритм розрахунку апарата високого тиску на міцність покажемо на прикладі реактора для надкритичної $\mathrm{CO}_{2}$ екстракції.

Для екстракції олії 3 насіння рослин використовують як екстрагент вуглекислий газ під великим тиском. Кінетика екстракції описується загальним рівнянням масообміну:

$$
\mu=k \cdot \Delta c \cdot F \cdot \tau,
$$

де $\mu$ - кількість екстрагованої речовини; $k$ коефіцієнт масопередачі; $\Delta c-$ середня різниця концентрацій екстрагованої речовини у твердій i рідкій фазах, яка залежить від тиску, температури, різниці потенціалів тощо; $F$ - площа міжфазної поверхні, для збільшення якої подрібнюють екстрагент; $\tau$ - час тривалості процесу.

Корпуси посудин реакторів виготовляють із нержавіючої сталі у вигляді циліндричних, конічних або сферичних оболонок. Найпростішим способом $\epsilon$ виготовлення з монолітного циліндра. Але внутрішній тиск у такому циліндрі не може перевищувати допустимих значень, які знаходять 3 виразу [6] $P_{\max } \leq \frac{\sigma_{T}}{\sqrt{3}},[\sigma]=\frac{\sigma_{T}}{1,5}=131 M П a$, для циліндра зі сталі 12Х18Н10Т, в якої $\sigma_{T}=196$ МПа і зовнішній діаметр прямує до безмежності, $P_{\max }=\frac{196}{1,5 \cdot \sqrt{3}}=113$ ППа . Для циліндричної посудини 3 розмірами діаметрів $209 \times 190$ і довжиною 1000 мм значення максимального тиску знаходять за формулою згідно з енергетичною теорією [4]: 


$$
P_{\max }=\frac{[\sigma] \cdot\left(1-k^{2}\right)}{\sqrt{3}}=\frac{131 \cdot(1-0,909)}{\sqrt{3}}=13 M \Pi a,
$$

де $k=\frac{r_{\text {зовн }}}{r_{\text {внутр }}}=\frac{20,9}{19}=0,909$.

Для екстракції олії 3 насіння амаранту технологічний процес потребує тиску до 50 МПа, і тому циліндр потрібно підсилювати. Для підвищення значення технологічного тиску в циліндрі використовують такі методи: 1) на монолітний циліндр із натягом напресовують один чи два циліндри [8]; 2) на поверхню циліндра встановлюють пружні кільця [10]; 3) поверхню циліндра обмотують металічною рулонованою стрічкою [1; 3]; 4) циліндр обмотують «сухим» або «мокрим» способом скляними, вуглецевими тощо волокнами або стрічками [3; 7].

Розглянемо виготовлення дво- $\mathrm{i}$ тришарового циліндра довжиною 1000 мм. Найменші еквівалентні напруження будуть тоді, коли радіус посадкової поверхні є середнє геометричне внутрішнього і зовнішнього радіусів [5].
Найбільший тиск, який може витримати монолітна циліндрична посудина, не може перевищувати $\frac{\sigma_{T}}{n \cdot \sqrt{3}}$, де $n=1,5-$ коефіцієнт запасу міцності [10].

Розглянемо розрахунок циліндричної посудини 3 розмірами діаметрів $209 \times 190$ і довжиною 1000 мм (див. рис., a) зі сталі 12Х18Н10Т, в якої границя плинності $\sigma_{T}=196$ МПа.

Значення еквівалентного нормального напруження за енергетичною теорією [2]:

$$
\begin{gathered}
\sigma_{\text {екв }}=\frac{P \cdot \sqrt{3}}{1-k_{1}^{2}} \leq[\sigma], \text { де } k_{1}=\frac{\eta_{1}}{r_{2}}=\frac{9,5}{10,45}=0,909 ; \\
{[\sigma]=\frac{\sigma_{T}}{n}=\frac{196}{1,5}=130,6 \text { MПa }} \\
\sigma_{\text {екв }}=\frac{50 \cdot \sqrt{3}}{1-0,909^{2}}=498 M \Pi a \geq[\sigma] .
\end{gathered}
$$

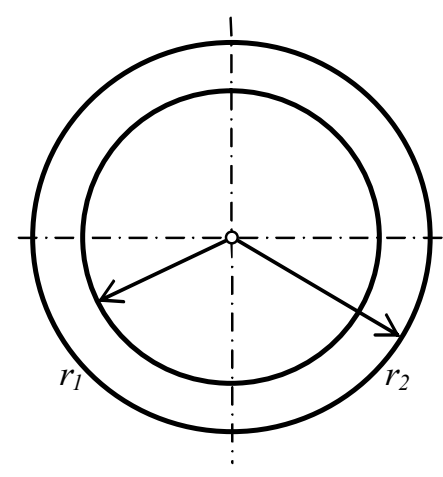

a)

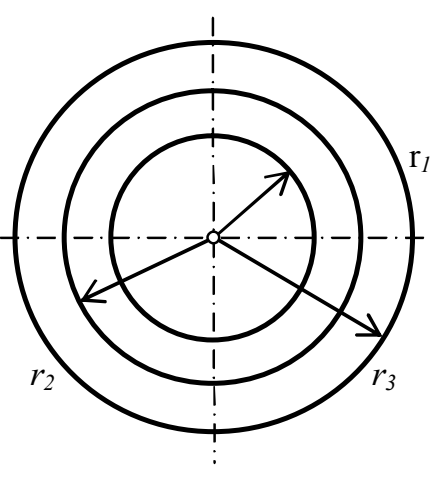

б)

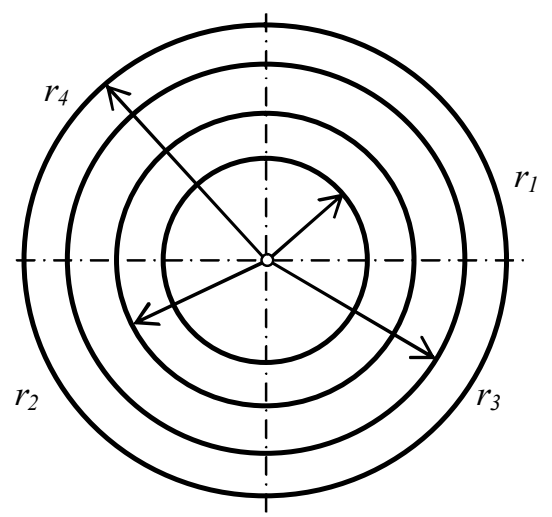

6)

Рис. Схеми шарованих посудин

Fig. Multilayer vessel diagrams

3 виразу для $\sigma_{e \kappa в}$ видно, що коли $\eta_{2} \rightarrow \infty$, $k_{1} \rightarrow 0$, то $\sigma_{e \kappa в}=P \cdot \sqrt{3}=87 M \Pi a \quad \epsilon$ максимальним, але менше за $[\sigma]$. Тобто виготовити монолітну посудину, щоб витримала такий тиск, неможливо [4; 7]. Для зменшення на внутрішньому діаметрі $\sigma_{e \kappa в}$ зробимо посудину двошаровою (див. рис., б).

Позначимо через $k_{1}=\frac{r_{1}}{r_{2}}, k_{2}=\frac{r_{2}}{r_{3}}, k=k_{1} \cdot k_{2}$.

Найменше значення $\sigma_{\text {екв }}$ буде тоді, коли $\eta 2$ дорівнюватиме середньому геометричному $\eta$ i r, тобто $\quad r_{2}=\sqrt{\eta \cdot r} \quad$ i $\quad k_{1}=k_{2}=\sqrt{k}, \quad$ а $r_{3}=\frac{r_{2}}{k_{2}}=\frac{10,45}{0,90}=11,5 \mathrm{~cm}, k=\frac{10,5}{11,5}=0,9534$.
Визначимо напруження на радіусі $r_{1}$ за формулою Ламе за дії лише внутрішнього тиску:

$$
\begin{gathered}
\sigma_{\theta}=\frac{1}{r_{3}^{2}-r_{1}^{2}} \cdot p \cdot r_{1}^{2} \cdot\left(\frac{r_{2}^{2}}{r_{1}^{2}}+1\right)= \\
=\frac{1}{11,2^{2}-9,5^{2}} \cdot 500 \cdot 9,5^{2}\left(\frac{9,5^{2}}{9,5^{2}}+1\right)= \\
=234,3 \text { MПa } \geq[\sigma] .
\end{gathered}
$$

Щоб зменшити $\sigma_{\theta}$, поставимо вимогу, щоб $\sigma_{\theta}$ на радіусі $r_{1}$ і $r_{2}$ були однакові і рівні $[\sigma]$. За формулою Ламе при $\eta=9,5 \mathrm{~cm}$ : 


$$
\begin{gathered}
\sigma_{\theta_{1}}=-\frac{1}{10,45^{2}-9,5^{2}} \cdot\left[p_{2} \cdot 10,45^{2} \cdot\left(\frac{9,5^{2}}{9,5^{2}}+1\right)-\right. \\
\left.-50,0 \cdot 9,5^{2}\left(\frac{10,45^{2}}{9,5^{2}}+1\right)\right]=130 \text { MПa. }
\end{gathered}
$$

Отримуємо рівняння:

$$
11,648 \cdot p_{2}+5262,6=1300 \text {. }
$$

Звідси $p_{2}=34 M \Pi а .3$ виразу $\sigma_{\theta_{2}}$ знайдемо 3

$$
\sigma_{\theta_{2}}=\frac{500+340}{x^{2}-10,45} \cdot 10,45^{2} \cdot\left(\frac{x^{2}}{10,45^{2}}+1\right)=130 \text { MП } a
$$

Звідси знаходимо $x=3=22,5 c m$, а значення натягу:

$$
\begin{gathered}
\delta=\frac{\alpha \cdot r_{2}}{E \cdot\left(r_{3}^{2}-r_{2}^{2}\right)} \cdot\left(p_{2} \cdot r_{2}^{2} \frac{r_{3}^{2}-r_{1}^{2}}{r_{2}^{2}-r_{1}^{2}}\right)= \\
=\frac{2 \cdot 10,45}{2 \cdot 10^{6} \cdot\left(22,5^{2}-10,45^{2}\right)} \cdot \\
\cdot 340 \cdot 10,45^{2} \frac{22,5^{2}-9,5^{2}}{10,45^{2}-9,5^{2}}=0.025 \mathrm{~cm} .
\end{gathered}
$$

Вага такої посудини буде:

$$
\begin{gathered}
G_{2}=\pi \cdot\left(r_{3}^{2}-r_{2}^{2}\right) \cdot l \cdot \gamma= \\
=\pi \cdot\left(22,5^{2}-9,5^{2}\right) \cdot 100 \cdot 7,8=1019 \kappa 2 .
\end{gathered}
$$

Оскільки двошарова посудина не є оптимальна, розрахуємо тришарову конструкцію (див. рис., в). Позначимо тиск між 1 і 2 циліндром через $p_{2}$, а між 2 і 3 - через $p_{3}$. Розміри $r_{3}$ i $r_{4}$ визначаємо з умови, що $k_{1}=k_{2}=k_{3}, r_{3}=12 \mathrm{~cm}, r_{4}=14 \mathrm{~cm}$.

Спочатку, вважаючи посудину монолітною, знайдемо напруження на границях шарів, рахуючи від центра, у шарах 1, 2, 3, 4 за формулою Ламе:

$$
\begin{gathered}
\sigma_{\theta_{1}}=-\frac{p \cdot r_{1}^{2}}{r_{4}^{2}-r_{1}^{2}} \cdot\left(\frac{r_{4}^{2}}{\eta}+1\right)= \\
=\frac{500 \cdot 9,5^{2}}{14^{2}-9,5^{2}} \cdot\left(\frac{14^{2}}{r^{2}}+1\right)=427 \cdot\left(\frac{14^{2}}{r^{2}}+1\right),
\end{gathered}
$$

і результат зведемо в таблицю.

Повні напруження від тиску і натягу запишуться так:

$$
\sigma_{\theta_{1}}=135,3-10,54 \cdot p_{2}
$$

$$
\begin{gathered}
\sigma_{\theta_{2}}=119+7,27 \cdot p_{2}-8,27 \cdot p_{3} \\
\sigma_{\theta_{1}}=100,7+6,54 \cdot p_{3}
\end{gathered}
$$

Таблиця. Результати досліджень напружень у стінках посудин

Table. The results of studies of stresses in the vessels walls

\begin{tabular}{|c|c|c|c|c|}
\hline & $\mathbf{1}$ & $\mathbf{2}$ & $\mathbf{3}$ & $\mathbf{4}$ \\
\hline$r$ & 9,5 & 10,45 & 12 & 14 \\
\hline$\sigma_{\theta}$ & 135,3 & 119 & 100,7 & 85,34 \\
\hline$\sigma_{\theta}^{p_{2}}$ & $-10,524 \cdot p_{2}$ & $7,27 \cdot p_{2}$ & & \\
\hline$\sigma_{\theta}^{p_{3}}$ & & $-8,27 \cdot p_{3}$ & $6,54 \cdot p_{3}$ & \\
\hline
\end{tabular}

Щоб розподіл напружень був рівномірним, напруження в точках 1, 2, 3 мають бути однаковими:

$135,3-10,54 \cdot p_{2}=119+7,27 \cdot p_{2}-8,27 \cdot p_{3}=$

$=140,7+6,54 \cdot p_{3}$.

3 рівнянь $p_{2}=1,937$ МПа $, p_{3}=2,19 M П а$ напруження в точках 1, 2, $3 \sigma_{\theta} \sim 115$ МПа.

Знайдемо натяг в т. 2 і т. 3 з виразу

$$
\begin{aligned}
& \delta_{2}=\frac{2 \cdot r_{2}}{E \cdot\left(r_{3}^{2}-r_{2}^{2}\right)} \cdot\left(p_{2} \cdot r_{2}^{2} \frac{r_{3}^{2}-r_{1}^{2}}{r_{2}^{2}-r_{1}^{2}}-p_{3} \cdot r_{3}^{2}\right) \text {, } \\
& \delta_{2}=\frac{2 \cdot 10,45}{2 \cdot 10^{6} \cdot\left(12^{2}-10,45^{2}\right)} \cdot \\
& \cdot\left(19,37 \cdot 10,45^{2} \frac{12^{2}-9,5^{2}}{10,45^{2}-9,5^{2}}-\right. \\
& \left.-21,9 \cdot 12^{2}\right)=0,000870 \mathrm{~cm} \\
& \delta_{3}=\frac{2 \cdot 12}{2 \cdot 10^{6} \cdot\left(12^{2}-10,45^{2}\right)} \cdot\left(-19,37 \cdot 10,45^{2}-\right. \\
& \left.-21,9 \cdot 12^{2} \cdot \frac{14^{2}-10,45^{2}}{14^{2}-12^{2}}\right)=0,001745 \mathrm{~cm} \text {. }
\end{aligned}
$$

Вага посудини буде $G_{3}=\pi \cdot\left(14^{2}-9,5^{2}\right)$. $\cdot 100 \cdot 7,8=259 \kappa 2$, тобто в 4 рази меншою від $G_{2}$. Виготовлення циліндрів довжиною 1000 мм 3 точністю до 5 мікрон є складною технологічною проблемою і потребує спеціального обладнання, але за теперішніх технологій це можливо. Розрахунки доцільніше виконувати з використанням сучасних методик і програмних комплексів типу ПАССАТ тощо [9]. 
Висновки. У процесі роботи були проаналізовані апарати високого тиску у вигляді циліндра в одно-, дво- і тришаровому виконанні, визначені еквівалентні напруження і натяги. Визначено вагові співвідношення. Апарати в тришаровому виконанні є міцними і найменш металомісткими, що суттєво зменшує вагу. Застосування на стадії проєктування більш економного тришарового циліндра дасть змогу побудувати економний, неметаломісткий апарат високого тиску й дотриматися всіх вимог чинних нормативних документів, зменшити металомісткість устаткування, збільшити надійність його роботи і знизити собівартість, підвищити якість продукції, що випускається.

\section{Бібліографічний список}

1. Бажанов В. Л. Пластинки и оболочки из стеклопластиков. Москва: Машиностроение, 1970. 407 с.

2. Биргер И. А., Пановко Я. Г. Прочность. Устойчивость. Колебания. Москва: Машиностроение, 1968. T. 2. 464 c.

3. Волокнистые и дисперсно-упрочненные конструкционные материалы. Москва: Машиностроение, 1976. 214 с.
4. ГОСТ Р52630-2012. Сосуды и аппараты стальные сварные. Общие технические условия. Москва: Стандартинформ, 2013.2 URL: https://pdfcoffee.com/gost-r-52630-2012pdf-pdf-free.html (дата обращения: 30.04.2021).

5. Конструювання i розрахунок посудин та апаратів високого тиску / В. В. Іванченко, І. М. Гєнкіна, Г. В. Тараненко, Ю. М. Штонда. Луганськ: Вид-во Східноукр. нац. ун-ту ім. В. Даля, 2010. 260 с.

6. НПАОП 0.00-1.59-87. Правила будови та безпечної експлуатації посудин, що працють під тиском. Київ: Держнаглядохоронпраці, 1998. 79 с.

7. Пономарев С. Д. Расчеты на прочность в машиностроении. Москва: Машиностроение, 1988. Т. 2. $974 \mathrm{c}$.

8. Тимошенко С. П., Войноровский-Кригар С. И. Пластины и оболочки. Москва: Машиностроение, 1986. $635 \mathrm{c}$.

9. Федірко П. П., Девін В. В., Ткачук В. С. Моделювання i розрахунок реактора високого тиску в програмному комплексі ПАССАТ. Подільський вісник: сільське господарство, техніка, економіка. 2017. Вип. 6. С. 72-78.

10. Хисматуллин Е. Р., Королев Е. М., Лифшиц В. И. Сосуды и трубопроводы высокого давления: справочник. Москва: Машиностроение, 1990. 384 с.

Стаття надійшла 07.05.2021 